\title{
Efficacy of human immunoglobulin injection and effects on serum inflammatory cytokines in neonates with acute lung injury
}

\author{
SHAOHUA WANG ${ }^{1}$, ZANMEI TANG $^{1}$, XUEMEI ZHENG $^{1}$, JIAN DENG $^{1}$ and ZHANGXING WANG ${ }^{2}$ \\ ${ }^{1}$ Neonatal Intensive Care Unit, Women and Children Health Institute of Futian, University of South China, Shenzen, \\ Guangdong 518033; ${ }^{2}$ Neonatal Intensive Care Unit, Longhua People's Hospital, Shenzhen, Guangdong 518109, P.R. China
}

Received November 5, 2019; Accepted October 15, 2020

DOI: $10.3892 /$ etm.2021.10363

\begin{abstract}
The present study aimed to explore the efficacy of intravenous immunoglobulin (IVIG) injection in neonates with acute lung injury (ALI) and assess its effects on serum inflammatory cytokine levels. The research subjects were 140 neonates with ALI who were evenly distributed into a control group (COG) and a study group (STG). The COG patients were treated routinely, whereas patients in the STG were administered IVIG in addition to the standard treatment received by the COG. The arterial partial pressure of oxygen $\left(\mathrm{PaO}_{2}\right), \mathrm{PaO}_{2}$ /fraction of inspired oxygen $\left(\mathrm{FIO}_{2}\right)$, mechanical ventilation time and hospitalization time were compared between the two groups. ELISA was used to determine the levels of interleukin-6 (IL-6) and tumor necrosis factor- $\alpha(\mathrm{TNF}-\alpha)$ in the patients before treatment and at 12 , 24 and $36 \mathrm{~h}$ after treatment. The Kaplan-Meier method was used to analyze the survival of the patients, including their survival for 30 days after treatment. The patients were divided into high and low cytokine expression groups based on their mean expression levels of serum IL-6 and TNF- $\alpha$ before treatment. After treatment, $\mathrm{PaO}_{2}$ and $\mathrm{PaO}_{2} / \mathrm{FiO} 2$ were significantly higher and mechanical ventilation and hospitalization time were reduced in the STG in comparison with the COG (all $\mathrm{P}<0.001)$. At 12, 24 and $36 \mathrm{~h}$ after treatment, serum IL-6 and TNF- $\alpha$ levels in the STG were lower than those in the COG (both $\mathrm{P}<0.05$ ). The 30-day survival rate after treatment was not significantly different between the two groups $(\mathrm{P}>0.05)$. The 30-day survival rate in the high IL-6 and high TNF- $\alpha$ expression COG was lower than that in the low IL-6 and low TNF- $\alpha$ expression COG (both $\mathrm{P}<0.05$ ). The results of the present study indicate that IVIG may improve pulmonary gas exchange, shorten the course of disease and reduce the inflammatory response in neonates with ALI.
\end{abstract}

Correspondence to: Dr Zhangxing Wang, Neonatal Intensive Care Unit, Longhua People's Hospital, 2 Jinglong Jianshe Road, Longhua, Shenzhen, Guangdong 518109, P.R. China

E-mail: junjun2cch@163.com

Key words: immunoglobulin, acute lung injury, neonate, inflammatory cytokine

\section{Introduction}

Acute lung injury (ALI) is characterized by high morbidity and mortality. Neonates are prone to ALI, particularly when they have infection, hypoxia or shock (1). The primary clinical manifestations of ALI are progressive hypoxemia and respiratory distress. ALI may lead to multiple organ dysfunction syndrome, multiple system organ failure and other life-threatening complications (2). Acute respiratory distress syndrome (ARDS) is a severe form of ALI (3). ARDS accounts for approximately $1-4 \%$ of all admissions to pediatric intensive care units, and $8-10 \%$ of patients with ARDS require mechanical ventilation worldwide. Despite progress in management of ARDS in pediatric intensive care units, ARDS still has a high mortality of 20-75\% (4) worldwide. Currently, there is no specific method in clinical practice for the treatment of ALI, though it is usually treated using mechanical ventilation and treatment methods for secondary organ injury and primary underlying diseases, and prognosis in patients is poor (5). Therefore, development of a more effective and safe treatment would be highly beneficial for children with ALI.

Intravenous immunoglobulin (IVIG) is a plasma product extracted from healthy human blood, with abundant immunoglobulin $\mathrm{G}(\operatorname{IgG})$ antibodies, which has an immunosuppressive and anti-inflammatory effect.It has been widely used in the treatment of various autoimmune and inflammatory diseases $(6,7)$, such as Kawasaki disease, sepsis and viral encephalitis (8-10). However, few studies have been conducted on the application of IVIG in neonates with ALI $(11,12)$. Currently, the pathogenesis of ALI is under investigation. An inflammatory cascade reaction triggered by lung injury can activate a variety of inflammatory cells to release a large number of inflammatory cytokines, including interleukin-6 (IL-6) and tumor necrosis factor- $\alpha$ (TNF- $\alpha)$. These inflammatory cytokines may damage pulmonary alveoli and pulmonary capillary structure by binding with receptors on endothelial cells in lung capillaries and alveolar epithelial cells. Therefore, a number of studies have suggested that inflammatory responses play an important role and are involved in the occurrence and development of ALI (13-15).

Currently, research into the treatment of ALI in neonates mainly focuses on mechanical ventilation and pulmonary surfactants and few studies have reported treatment with IVIG (16). Therefore, the present study was designed to explore 
the efficacy of IVIG and its effects on serum inflammatory cytokines in neonates with ALI.

\section{Materials and methods}

Research subjects. The research subjects were 140 neonates with ALI who were admitted to the Neonatal Intensive Care Unit of Longhua People's Hospital (Shenzhen, China) between May 2016 and December 2018. Subjects were randomly assigned to the control group (COG) or the study group (STG), with 70 patients in each group. After 30 days' treatment, there were 60 patients alive in the COG and 66 patients alive in STG. The inclusion criteria were that all patients met the diagnostic criteria for ALI (17). Patients with congenital heart disease or congenital lung development defects, patients whose families disagreed to their participation or whose etiology was unclear, and patients with a length of labor $>1$ day were excluded. The parents or guardians of the patients signed the informed consent forms after understanding the study, and the experiment was approved by the Medical Ethics Committee of Longhua People's Hospital (Shenzhen, China; approval no. 20180713).

Treatment methods. The patients all underwent chest X-ray, oxygenation index and oxygen partial pressure examinations. Patients in the COG were treated with the following routine treatment scheme: At 0, 12, 24 and $36 \mathrm{~h}$, each of the patients was hooked up to a ventilator in pressure support ventilation and synchronized intermittent mandatory ventilation mode [exhaled tidal volume, $6 \mathrm{ml} / \mathrm{kg}$; arterial partial pressure of oxygen $\left(\mathrm{PaO}_{2}\right),>8.24 \mathrm{kPa}$; arterial carbon dioxide partial pressure $\left.\left(\mathrm{PaCO}_{2}\right),<5.34 \mathrm{kPa}\right)$, and they were also provided water and treatment to ensure the same electrolyte balance, anti-infection and nutritional support at the same time. Patients in the STG were treated with IVIG (cat. no. S10980061; Shanghai RAAS Blood Products Co., Ltd.) in addition to the treatment used for the COG. IVIG was administered by intravenous drip at $1 \mathrm{~g} / \mathrm{kg}$ weight /day for 2 days consecutively. Standard treatment was administered for the subsequent 5 days. Both groups were treated for 7 days.

Observation indices. The $\mathrm{PaO}_{2}$ and fraction of inspired oxygen $\left(\mathrm{FIO}_{2}\right)$ at $1 \mathrm{~h}$ before treatment and the mechanical ventilation status and hospitalization time of patients in the two groups were recorded and their 30-day survival rates were analyzed.

Determination of inflammatory cytokine levels. Venous blood from the elbow of the arm $(3 \mathrm{ml})$ was sampled from each patient in the two groups at $1 \mathrm{~h}$ before and at 12,24 and $36 \mathrm{~h}$ after treatment, respectively. The clotted sampled blood was centrifuged at $300 \mathrm{x} g$ to extract the supernatant, which was stored in a refrigerator at $-20^{\circ} \mathrm{C}$ for subsequent analysis.

ELISA was used to determine the serum IL- 6 and TNF- $\alpha$ levels of patients from the two groups in accordance with the manufacturer's instructions [human IL-6 ELISA (cat. no. KIT10395A; Sino Biological Inc.) and human TNF- $\alpha$ ELISA (cat. no. FK-R0122; Shanghai FKBIO Co., Ltd.)]. A well for samples to be determined, a standard well and a blank well were set. No enzyme-labeled reagent or sample was added into the blank well, and $100 \mu 1$ of samples and $100 \mu 1$ of standards were added into the well for samples to be determined and standard well, respectively, and mixed well. Both samples to be determined and standard wells were covered with a film and incubated at $37^{\circ} \mathrm{C}$ for $2 \mathrm{~h}$. The liquid was discarded and the plate was patted dry, and $100 \mu \mathrm{l}$ each of working fluid A and fluid B was added. The optical density of each well at a wavelength of $450 \mathrm{~nm}$ was measured using an enzyme mark instrument (Wuhan USCN Business Co., Ltd.), and the cytokine concentration of each sample was calculated.

Statistical analysis. The data were statistically analyzed using SPSS 21.0 (IBM Corp.) and visualized in figures using GraphPad Prism 7 (GraphPad Software, Inc.). Patient numbers are presented as [n(\%)], and differences in rates were analyzed using $\chi^{2}$ test. Measurement data are presented as the mean $\pm \mathrm{SD}$. Measurement data between two groups were analyzed using an independent samples Student's t-test. Two-way ANOVA was employed to analyze the data in Fig. 1. Comparison between the groups was performed by analyzing the data with Bonferroni's post hoc test.

Repeated measures data were analyzed using a repeated measures ANOVA with Bonferroni's post hoc test. The Kaplan-Meier method was used to draw survival curves of the patients and log-rank test was adopted for analysis. $\mathrm{P}<0.05$ was considered to indicate a statistically significant difference.

\section{Results}

Comparison of general data between the two groups. The COG consisted of 40 male and 30 female neonates, with a mean age of $7.92 \pm 3.36 \mathrm{~h}$, a mean fetal age of $36.23 \pm 2.21$ gestational weeks and a mean weight of $2.79 \pm 0.33 \mathrm{~kg}$. In terms of primary diseases, the COG had 29 patients with asphyxia, 18 with pneumonia, 13 with septicemia and 10 with meconium aspiration syndrome. In terms of delivery mode, 31 patients were delivered through vaginal and 39 through cesarean delivery. The STG consisted of 32 male and 38 female neonates, with a mean average age of $8.64 \pm 2.88 \mathrm{~h}$, a mean fetal age of $35.81 \pm 2.68$ gestational weeks and a mean weight of $2.87 \pm 0.41 \mathrm{~kg}$. In terms of primary diseases, the COG had 21 patients with asphyxia, 25 with pneumonia, 9 with septicemia and 15 with meconium aspiration syndrome. In terms of delivery mode, 26 patients were delivered through vaginal delivery and 44 through cesarean. General data, including sex, age, fetal age, weight, primary diseases and delivery mode were not significantly different between the two groups (all $\mathrm{P}>0.05$; Table I).

Comparison of $\mathrm{PaO}_{2}$ and $\mathrm{PaO}_{2} / \mathrm{FIO}_{2}$ before and after treatment between the two groups. $\mathrm{PaO}_{2}$ and $\mathrm{PaO}_{2} / \mathrm{FIO}_{2}$ were not significantly different before treatment between the two groups $(\mathrm{P}>0.05)$, whereas $\mathrm{PaO}_{2}$ and $\mathrm{PaO}_{2} / \mathrm{FIO}_{2}$ significantly increased after treatment (both $\mathrm{P}<0.05$ ). $\mathrm{PaO}_{2}$ and $\mathrm{PaO}_{2} / \mathrm{FIO}_{2}$ in the STG were higher than those in the COG (both $\mathrm{P}<0.05$; Fig. 1).

Comparison of mechanical ventilation and hospitalization time between the two groups. The mechanical ventilation and hospitalization times of the STG patients were $54.53 \pm 10.17 \mathrm{~h}$ 
Table I. Comparison of general data between the two groups.

\begin{tabular}{|c|c|c|c|c|}
\hline Characteristic & Control group $(\mathrm{n}=70)$ & Study group $(\mathrm{n}=70)$ & $\chi^{2} /$ t-statistic & P-value \\
\hline Sex & & & 1.830 & 0.176 \\
\hline Male & $40(57.14)$ & $32(45.71)$ & & \\
\hline Female & $30(42.86)$ & $38(54.29)$ & & \\
\hline Mean age, days & $0.33 \pm 0.14$ & $0.36 \pm 0.12$ & 1.361 & 0.176 \\
\hline Fetal age, weeks & $36.23 \pm 2.21$ & $35.81 \pm 2.68$ & 1.012 & 0.314 \\
\hline Average weight, $\mathrm{kg}$ & $2.79 \pm 0.33$ & $2.87 \pm 0.41$ & 1.478 & 0.142 \\
\hline Primary diseases & & & 2.935 & 0.231 \\
\hline Asphyxia & $29(41.43)$ & $21(30.00)$ & & \\
\hline Pneumonia & $18(25.71)$ & $25(35.71)$ & & \\
\hline Septicemia & $13(18.57)$ & $9(12.86)$ & & \\
\hline Meconium aspiration syndrome & $10(14.29)$ & $15(21.43)$ & & \\
\hline Delivery mode & & & 0.740 & 0.390 \\
\hline Vaginal delivery & $31(44.29)$ & $26(37.14)$ & & \\
\hline Cesarean delivery & $39(55.71)$ & $44(62.86)$ & & \\
\hline
\end{tabular}

Data are displayed as $\mathrm{n}(\%)$ or the mean \pm standard deviation.
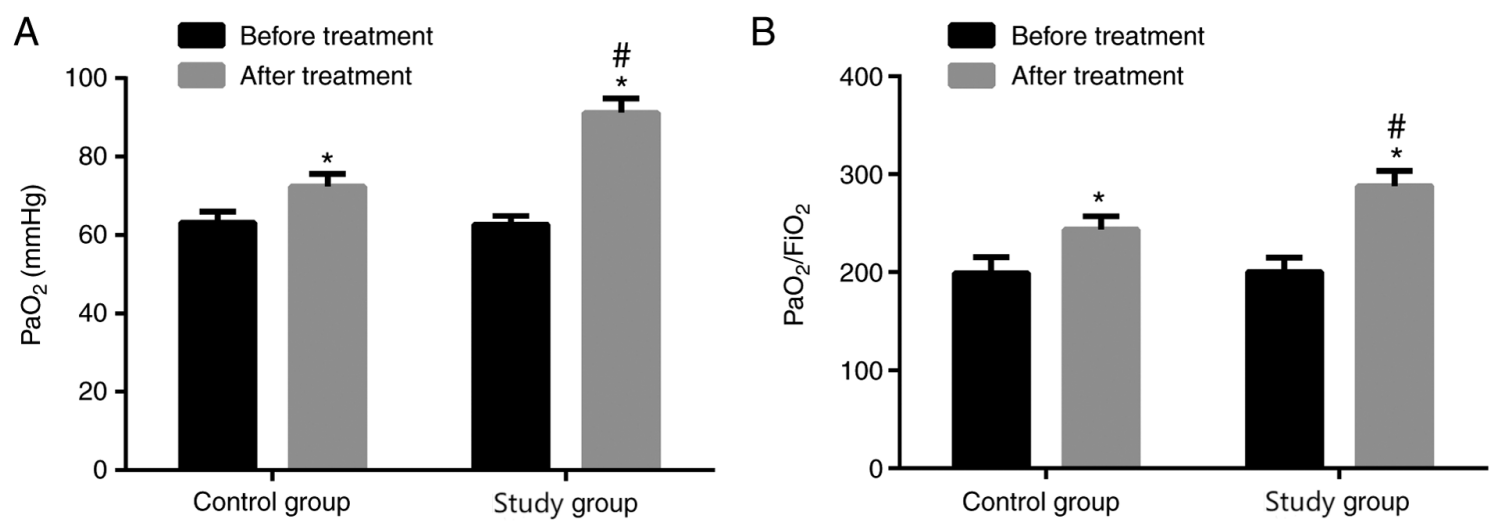

Figure 1. Comparison of $\mathrm{PaO}_{2}$ and $\mathrm{PaO}_{2} / \mathrm{FiO}_{2}$ before and after treatment between the STG and COG. (A) Comparison of PaO 2 before and after treatment between the two groups. (B) Comparison of $\mathrm{PaO}_{2} / \mathrm{FiO}_{2}$ before and after treatment between the two groups. "P<0.05 vs. the respective before treatment group; and ${ }^{\#} \mathrm{P}<0.05$ vs. $\mathrm{COG}$ after treatment. $\mathrm{PaO}_{2}$, partial pressure of oxygen; $\mathrm{FiO}_{2}$, fraction of inspired oxygen; COG, control treated group; STG, study treatment group.

and $17.46 \pm 3.76$ days, and of the COG patients $75.45 \pm 13.30 \mathrm{~h}$ and $3.64 \pm 4.27$ days. Thus, the STG patients experienced significantly shorter durations of mechanical ventilation and hospitalization time than the COG patients (both $\mathrm{P}<0.001$; Table II).

Comparison of serum IL- 6 and TNF- $\alpha$ levels before and after treatment between the two groups. The serum IL-6 and TNF- $\alpha$ levels at 12, 24 and $36 \mathrm{~h}$ after treatment in the two groups were significantly lower than those before treatment (all $\mathrm{P}<0.05$ ). The serum IL-6 and TNF- $\alpha$ levels at 24 and $36 \mathrm{~h}$ after treatment were lower than those at $12 \mathrm{~h}$ after treatment (both $\mathrm{P}<0.05$ ). The serum IL-6 and TNF- $\alpha$ levels at $36 \mathrm{~h}$ after treatment were lower than those at $24 \mathrm{~h}$ after treatment (both $\mathrm{P}<0.05)$. The serum IL-6 and TNF- $\alpha$ levels before treatment were not significantly different between the two groups (both $\mathrm{P}>0.05$ ), whereas the serum IL-6 and TNF- $\alpha$ levels at 12, 24 and $36 \mathrm{~h}$ after treatment in the STG were significantly lower than those in the COG ( $\mathrm{P}<0.05$; Fig. 2).
Comparison of 30-day survival rate after treatment between the two groups. The follow-up results showed that the 30-day survival rate was not different between the COG and STG patients [94.28\% (66/70) vs. 85.71\% (60/70); P>0.05; Fig. 3].

Effects of IL-6 and TNF- $\alpha$ levels on the survival rate of patients. The patients in the COG were divided into high $(\mathrm{n}=41$; expression $\geq 185.45 \mathrm{pg} / \mathrm{ml})$ and low $(\mathrm{n}=29$; expression $<185.45 \mathrm{pg} / \mathrm{ml}$ ) IL- 6 expression groups based on their mean serum IL-6 level before treatment. They were also divided into high $(\mathrm{n}=32$; expression $\geq 121.13 \mathrm{pg} / \mathrm{ml}$ ) and low ( $\mathrm{n}=38$; expression $<121.13 \mathrm{pg} / \mathrm{ml}$ ) TNF- $\alpha$ expression groups based on their mean serum TNF- $\alpha$ level before treatment. The 30 -day survival rate of the high IL-6 expression group was significantly lower than that in the low IL-6 expression group [68.29\% (28/41) vs. $96.55 \%(28 / 29) ; \mathrm{P}<0.05]$ and that in the high TNF- $\alpha$ expression group was also lower than that in the low TNF- $\alpha$ expression group [65.63\% (21/32) vs. 92.11\% (35/38); P<0.05; Fig. 4]. 
Table II. Comparison of mechanical ventilation and hospitalization time between the two groups.

\begin{tabular}{|c|c|c|c|c|c|c|}
\hline Group & $\begin{array}{c}\text { Mechanical } \\
\text { ventilation time, } \mathrm{h}\end{array}$ & t-statistic & P-value & $\begin{array}{l}\text { Hospitalization } \\
\text { time, days }\end{array}$ & t-statistic & P-value \\
\hline Control group $(n=70)$ & $75.45 \pm 13.30$ & 10.454 & $<0.001$ & $23.64 \pm 4.27$ & 9.088 & $<0.001$ \\
\hline Study group $(n=70)$ & $54.53 \pm 10.17$ & & & $17.46 \pm 3.76$ & & \\
\hline
\end{tabular}

Data are presented as the mean \pm standard deviation.
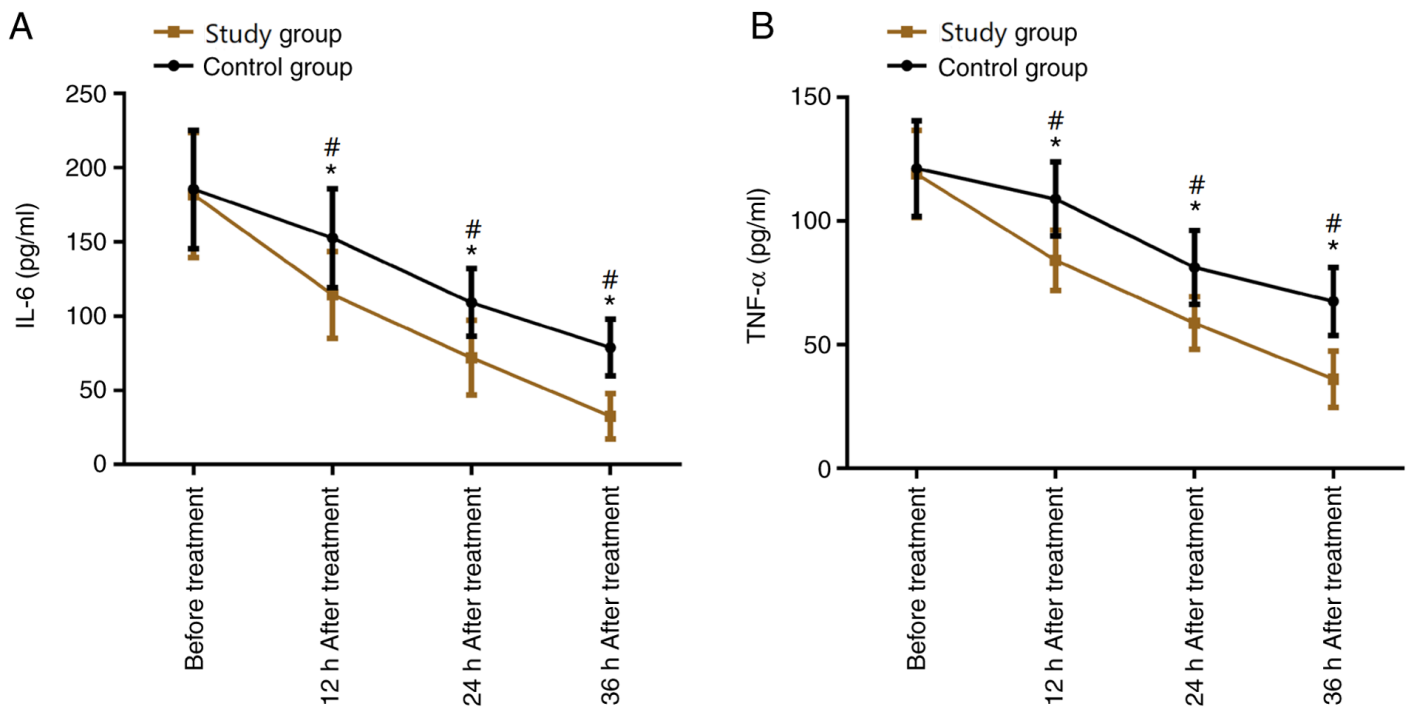

Figure 2. Comparison of serum IL-6 and TNF- $\alpha$ levels at different time points between the STG and COG. (A) Comparison of serum IL-6 level at different time points between the two groups. (B) Comparison of serum TNF- $\alpha$ level at different time points between the two groups. " $\mathrm{P}<0.05$ vs. COG; ${ }^{~} \mathrm{P}<0.05$ vs. before treatment. COG, control treated group; STG, study treatment group; IL-6, interleukin-6; TNF- $\alpha$, tumor necrosis factor- $\alpha$.

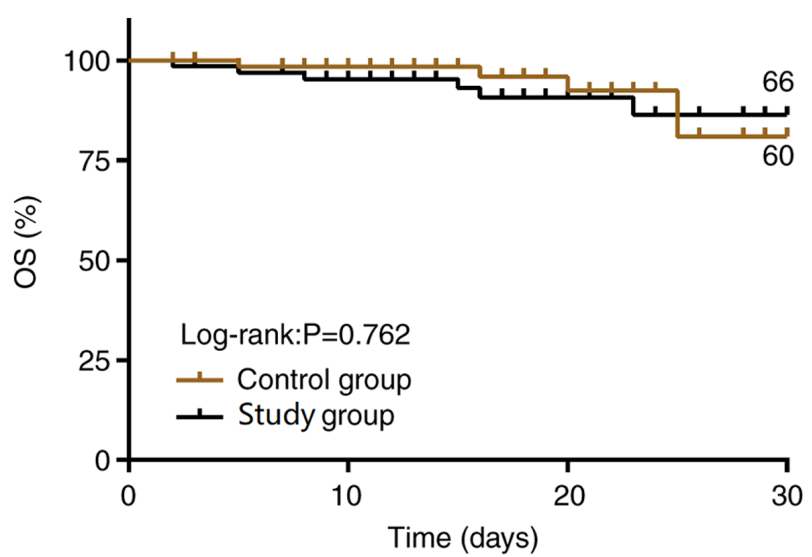

Figure 3. Comparison of the survival rate between the STG and the COG. COG, control treated group; STG, study treatment group; OS, overall survival.

\section{Discussion}

The pathological basis of ALI is that damaged lung capillary endothelial cells and alveolar epithelial cells cause edema in pulmonary alveoli and the pulmonary interstitium, leading to acute hypoxic respiratory insufficiency or failure and pathophysiological characteristics, such as lung volume reduction, lung compliance decline and severe ventilation/blood flow disproportion (18). ALI is usually treated with respiratory support measures in clinical practice. In addition, with the continuous progress of studies on ALI, most researchers support the hypothesis that anti-inflammatory treatment can be beneficially applied in ALI $(19,20)$. Clinically, nonspecific anti-inflammatory treatment is administered with use of glucocorticoid, immunoglobulin and non-steroidal anti-inflammatory preparations (21). However, glucocorticoid and non-steroidal anti-inflammatory preparations can lead to various noxious toxic side effects when used in neonates; thus, they are not suitable for the treatment of ALI in this group of patients (21). Therefore, the present study adopted IVIG combined with mechanical ventilation to treat neonates with ALI.

With the ability to regulate macrophage activity, IVIG not only can inhibit macrophage overactivation but can also suppress $\mathrm{T}$ lymphocyte and natural killer cell activity, thus lowering autoimmune reactions (22). In addition, IVIG contains a large number of specific antibodies that can regulate synthesis and release of inflammatory cytokines; hence, it has a strong anti-inflammatory effect $(23,24)$. The efficacy of respiratory support is judged on monitored respiratory mechanics. $\mathrm{PaO}_{2}$ can directly reflect hypoxemia and its severity, and $\mathrm{PaO}_{2} / \mathrm{FIO}_{2}$ can reflect the extent of damage to pulmonary vessels and alveoli (25). Therefore, the present study selected $\mathrm{PaO}_{2}$ and $\mathrm{PaO}_{2} / \mathrm{FIO}_{2}$ as evaluation indices 
A

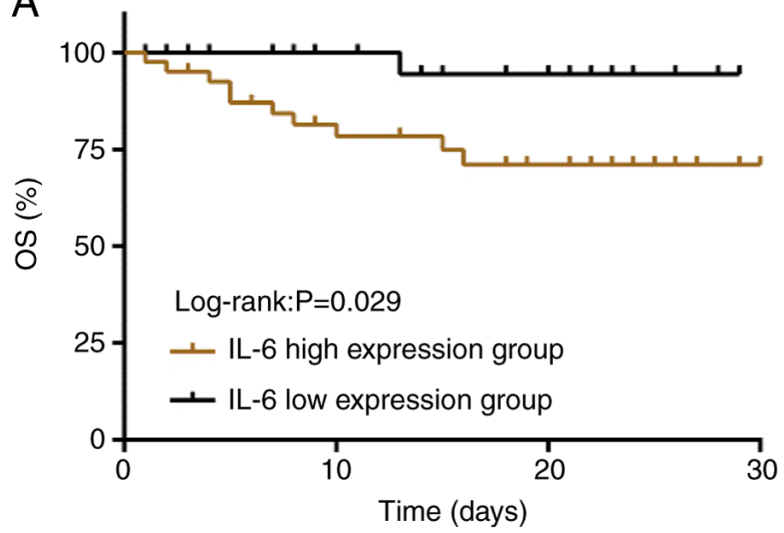

B

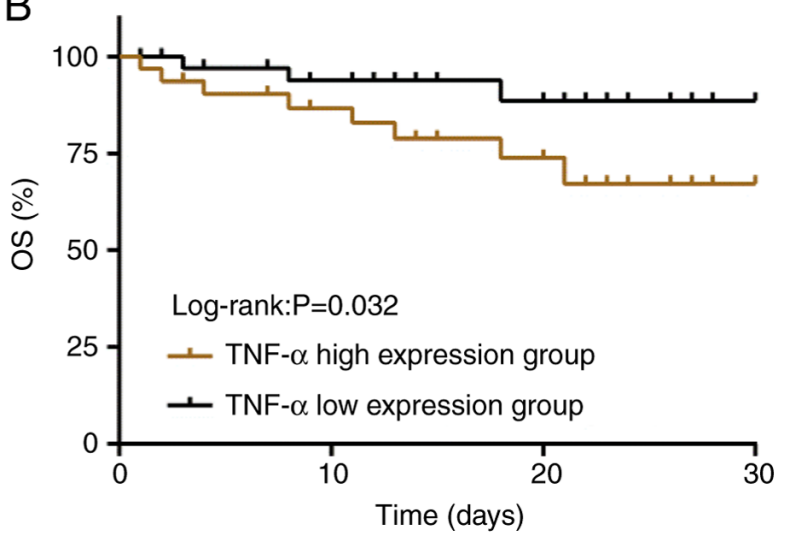

Figure 4. Comparisons of the 30-day survival rate between the high and low IL- 6 expression groups and between the high and low TNF- $\alpha$ expression groups. (A) Comparison of the survival rate between the high and low IL-6 expression groups. (B) Comparison of the survival rate between the high and low TNF- $\alpha$ expression groups. IL-6, interleukin-6; TNF- $\alpha$, tumor necrosis factor- $\alpha$; OS, overall survival.

for pulmonary function of neonates with ALI. In addition to measures of mechanical ventilation and PS, the present study additionally used IVIG through intravenous injection to neonates with ALI. Subsequently, $\mathrm{PaO}_{2}$ and $\mathrm{PaO}_{2} / \mathrm{FIO}_{2}$ in the STG were significantly higher than those in the COG patients, and the STG patients experienced significantly shorter mechanical ventilation and hospitalization times than the COG patients, suggesting that mechanical ventilation and intravenous injection of IVIG could improve pulmonary gas exchange in neonates with ALI. Subsequently, the 30-day survival rate of neonates with ALI in the two groups was analyzed, and no significant differences were found between the two groups, indicating that though mechanical ventilation and intravenous injection of IVIG appeared to improve pulmonary gas exchange in neonates with ALI it had no effect on their short-term survival rate.

ALI is a stage of systemic inflammatory response syndrome and an earlier study indicated that the inflammatory response is one of the main reasons for progression of ALI into ARDS (26). Due to ALI, inflammatory cells are activated, and these cells release a large number of pro-inflammatory cytokines, causing cell metabolism dysfunction and aggregation of a large number of neutrophil cells to inflammatory sites, where they then release a large number of oxygen free radicals, causing oxidative stress injuries $(27,28)$. IL-6, a pro-inflammatory and immunomodulatory cytokine, can help the host defend against infection and tissue damage, and its abnormal expression in the human body can lead to various diseases, such as dyslipidemia, hyperinsulinemia, diabetes, hypertension and cardiovascular diseases (29). TNF- $\alpha$ is a protein produced by activated macrophages and monocytes, which participates in the human inflammatory and immune response, and is crucial in maintaining homeostasis (30). Lowering TNF- $\alpha$ levels or blocking TNF- $\alpha$ binding to its receptors can alleviate inflammatory injury (31). A study by Chu et al (32) showed that TNF- $\alpha$ and IL- 6 were highly expressed in ALI mouse models and that their expression levels decreased after treatment. A study by Wang et al (33) indicated that children with ALI treated with probiotics had significantly decreased serum IL-6 and TNF- $\alpha$ levels than control patients, which were negatively correlated with pulmonary artery pressure. The results of the present study showed that in both groups there was a significant decrease in serum IL- 6 and TNF- $\alpha$ levels after treatment when compared with pre-treatment levels, and the STG showed a more significant decrease, similarly to the above cited study results (33), suggesting that IVIG can effectively reduce inflammatory response in neonates with ALI. If large doses of IVIG are used frequently, IVIG may inhibit the production of immunoglobulins in autoimmune cells. However, IVIG is an allergen to the human body and excessive use can cause allergic reactions (34).

In the present study, the mean serum IL- 6 and TNF- $\alpha$ levels in patients in the COG before treatment were taken into consideration to analyze the effects of their high and low expression levels on the survival rate. Patients with high expression levels of serum IL-6 and TNF- $\alpha$ showed a significantly lower 30-day survival rate than those with low expressions, suggesting that the probable survival of neonates with ALI can be evaluated by determining their serum IL- 6 and TNF- $\alpha$ expressions.

The research subjects in this study were selected in strict accordance with inclusion and exclusion criteria, and no significant differences were found between the two groups in general data, including sex, age, fetal age, weight, primary diseases, and delivery mode, which reduced effects of other factors on the study results and ensured the preciseness of the study. However, this study has some limitations. The survival rate of patients was only recorded for 30 days after treatment and long-term follow-up to understand their long-term survival rate was not performed. In addition, the mechanism of action of IVIG in treating neonates with ALI was neither thoroughly or comprehensively explored as it was not possible to assess the optimal dosage, treatment course and applicable conditions of IVIG. Inflammatory chemokines, such as monocyte chemoattractant protein-1 (MCP-1) are also important in ALI (35) and were not assessed in the present study. These limitations will be addressed in the future.

In summary, IVIG treatment may improve the pulmonary gas exchange of neonates with ALI, shorten their course of disease and reduce the inflammatory response. However, few studies have reported on IVIG as treatment for neonates with ALI and therefore more research is needed. 


\section{Acknowledgements}

Not applicable.

\section{Funding}

This work was supported by a grant from the Key Project of Science and Technology Innovation Bureau of Futian District, Shenzhen, 2019 (grant no. FTWS2019004).

\section{Availability of data and materials}

The datasets used and/or analyzed during the current study are available from the corresponding author on reasonable request.

\section{Authors' contributions}

SW and ZW designed the study, SW wrote the draft and ZW reviewed the manuscript. ZT, XZ and JD analyzed the data and performed the statistical analysis. All authors read and approved the final manuscript.

\section{Ethics approval and consent to participate}

The parents or guardians of patients signed informed consent forms after understanding the study, and the experiment was approved by the Medical Ethics Committee of Longhua People's Hospital (Shenzhen, China).

\section{Patient consent for publication}

Not applicable.

\section{Competing interests}

The authors declare that they have no competing interests.

\section{References}

1. Li Y, Wu R, Tian Y, Yu M, Tang Y, Cheng $\mathrm{H}$ and Tian Z: $\mathrm{RAGE} / \mathrm{NF}-\kappa \mathrm{B}$ signaling mediates lipopolysaccharide induced acute lung injury in neonate rat model. Int J Clin Exp Med 8: 13371-13376, 2015.

2. Jin Z, Chun Suen K and Ma D: Perioperative 'remote' acute lung injury: Recent update. J Biomed Res 31: 197-212, 2017.

3. Rajasekaran S, Pattarayan D, Rajaguru P, Sudhakar Gandhi PS and Thimmulappa RK: MicroRNA regulation of acute lung injury and acute respiratory distress syndrome. J Cell Physiol 231: 2097-2106, 2016.

4. Gupta S, Sankar J, Lodha R and Kabra SK: Comparison of prevalence and outcomes of pediatric acute respiratory distress syndrome using Pediatric Acute Lung Injury Consensus Conference criteria and Berlin definition. Front Pediatr 6: 93 , 2018.

5. Perl M, Chung C-S, Perl U, Lomas-Neira J, de Paepe M, Cioffi WG and Ayala A: Fas-induced pulmonary apoptosis and inflammation during indirect acute lung injury. Am J Respir Crit Care Med 176: 591-601, 2007.

6. Perez EE, Orange JS, Bonilla F, Chinen J, Chinn IK, Dorsey M, El-Gamal Y, Harville TO, Hossny E, Mazer B, et al: Update on the use of immunoglobulin in human disease: A review of evidence. J Allergy Clin Immunol 139: S1-S46, 2017.

7. Wang Y and Scott DE: Development of a complement-mediated hemolysis assay for Immune globulin intravenous products and characterization of lots associated with clinical hemolysis. 2017.

8. Shulman ST: Intravenous immunoglobulin for the treatment of Kawasaki disease. Pediatr Ann 46: e25-e28, 2017.
9. Tagami T, Matsui H, Fushimi K and Yasunaga H: Intravenous immunoglobulin use in septic shock patients after emergency laparotomy. J Infect 71: 158-166, 2015.

10. Rayamajhi A, Nightingale S, Bhatta NK, Singh R, Kneen R, Ledger E, Bista KP, Lewthwaite P, Mahaseth C, Turtle L, et al: A preliminary randomized double blind placebo-controlled trial of intravenous immunoglobulin for Japanese encephalitis in Nepal. PLoS One 10: e0122608, 2015.

11. Fakhari Z, Farsaei S and Sabzghabaee AM: Predicting factors for the pattern of intravenous immunoglobulin utilization in a Middle Eastern University Hospital. J Res Pharm Pract 7: 188-194, 2018.

12. Hartung HP, Mouthon L, Ahmed R, Jordan S, Laupland KB and Jolles S: Clinical applications of intravenous immunoglobulins (IVIg) - beyond immunodeficiencies and neurology. Clin Exp Immunol 158 (Suppl 1): 23-33, 2009.

13. Jing W, Chunhua M and Shumin W: Effects of acteoside on lipopolysaccharide-induced inflammation in acute lung injury via regulation of NF- $\mathrm{KB}$ pathway in vivo and in vitro. Toxicol Appl Pharmacol 285: 128-135, 2015.

14. Jiang W, Luo F, Lu Q, Liu J, Li P, Wang X, Fu Y, Hao K, Yan T and Ding X: The protective effect of Trillin LPS-induced acute lung injury by the regulations of inflammation and oxidative state. Chem Biol Interact 243: 127-134, 2016.

15. Mokra D and Kosutova P: Biomarkers in acute lung injury. Respir Physiol Neurobiol 209: 52-58, 2015.

16. Altirkawi K: Surfactant therapy: The current practice and the future trends. Sudan J Paediatr 13: 11-22, 2013.

17. Demirakça S, Dötsch J, Knothe C, Magsaam J, Reiter HL, Bauer J and Kuehl PG: Inhaled nitric oxide in neonatal and pediatric acute respiratory distress syndrome: Dose response, prolonged inhalation, and weaning. Crit Care Med 24: 1913-1919, 1996.

18. Lai D, Xia J, Wang J, Wei X, Qian J, Lou Q, Ren X and Huang X: The effect of paraquat on voltage-dependent anion channel and caspase-3, 8, 9 in the mitochondria of rat lung. Zhonghua Lao Dong Wei Sheng Zhi Ye Bing Za Zhi 33: 363-365, 2015 (In Chinese).

19. Zimmermann KK, Spassov SG, Strosing KM, Ihle PM, Engelstaedter H, Hoetzel A and Faller S: Hydrogen sulfide exerts anti-oxidative and anti-inflammatory effects in acute lung injury. Inflammation 41: 249-259, 2018.

20. Li SJ, Wang XJ, Hu JB, Kang XQ, Chen L, Xu XL, Ying XY, Jiang SP and Du YZ: Targeting delivery of simvastatin using ICAM-1 antibody-conjugated nanostructured lipid carriers for acute lung injury therapy. Drug Deliv 24: 402-413, 2017.

21. Becker DE: Basic and clinical pharmacology of glucocorticosteroids. Anesth Prog 60: 25-31, quiz 32, 2013.

22. Navegantes KC, de Souza Gomes R, Pereira PA, Czaikoski PG, Azevedo $\mathrm{CH}$ and Monteiro MC: Immune modulation of some autoimmune diseases: The critical role of macrophages and neutrophils in the innate and adaptive immunity. J Transl Med 15: 36, 2017.

23. Gadian J, Kirk E, Holliday K, Lim M and Absoud M: Systematic review of immunoglobulin use in paediatric neurological and neurodevelopmental disorders. Dev Med Child Neurol 59: 136-144, 2017.

24. Ma XY, Li Z, Wang XJ, Ye JJ, Ma YP and Li Y: Clinical efficacy of different doses of gamma globulin combined with glucocorticoid in treatment of moderate/severe acute Guillain-Barré syndrome in children: A comparative analysis. Zhongguo Dang Dai Er Ke Za Zhi 18: 1286-1290, 2016 (In Chinese).

25. Viasus D, Garcia-Vidal C, Simonetti AF, Dorca J, Llopis F, Mestre M, Morandeira-Rego F and Carratalà J: The effect of simvastatin on inflammatory cytokines in community-acquired pneumonia: A randomised, double-blind, placebo-controlled trial. BMJ Open 5: e006251, 2015.

26. Fang $\mathrm{Y}, \mathrm{Xu} \mathrm{P}, \mathrm{Gu} \mathrm{C}$, Wang $\mathrm{Y}, \mathrm{Fu} \mathrm{XJ}, \mathrm{Yu}$ WR and Yao M: Ulinastatin improves pulmonary function in severe burn-induced acute lung injury by attenuating inflammatory response. J Trauma 71: 1297-1304, 2011.

27. Gao M, Xie B, Gu C, Li H, Zhang F and Yu Y: Targeting the proinflammatory cytokine tumor necrosis factor- $\alpha$ to alleviate cardiopulmonary bypass-induced lung injury (review). Mol Med Rep 11: 2373-2378, 2015.

28. Massey VL, Poole LG, Siow DL, Torres E, Warner NL, Schmidt RH, Ritzenthaler JD, Roman J and Arteel GE: Chronic alcohol exposure enhances lipopolysaccharide-induced lung injury in mice: Potential role of systemic tumor necrosis factor-alpha. Alcohol Clin Exp Res 39: 1978-1988, 2015. 
29. Kang S, Tanaka $\mathrm{T}$ and Kishimoto T: Therapeutic uses of anti-interleukin-6 receptor antibody. Int Immunol 27: 21-29, 2015.

30. Wang L, Chen Q, Shi C, Lv H, Xu X and Yu L: Changes of serum TNF- $\alpha$, IL-5 and IgE levels in the patients of mycoplasma pneumonia infection with or without bronchial asthma. Int J Clin Exp Med 8: 3901-3906, 2015.

31. Han CL and Zhao SL: Intravenous immunoglobulin gamma (IVIG) versus IVIG plus infliximab in young children with Kawasaki disease. Med Sci Monit 24: 7264-7270, 2018.

32. Chu L, Zhu F, Zhou W, Du Z, Li J, Wang X, Wang L and Liu A Baicalein attenuates acute lung injury induced by intestinal ischemia/reperfusion via inhibition of nuclear factor- $\kappa \mathrm{B}$ pathway in mice. Zhonghua Wei Zhong Bing Ji Jiu Yi Xue 29: 228-232, 2017 (In Chinese)
33. Wang Y, Gao L, Yang Z, Chen F and Zhang Y: Effects of probiotics on ghrelin and lungs in children with acute lung injury: A double-blind randomized, controlled trial. Pediatr Pulmonol 53: 197-203, 2018.

34. Galli SJ, Tsai M and Piliponsky AM: The development of allergic inflammation. Nature 454: 445-454, 2008

35. Deshmane SL, Kremlev S, Amini S and Sawaya BE: Monocyte chemoattractant protein-1 (MCP-1): An overview. J Interferon Cytokine Res 29: 313-326, 2009.

(c) (i) () $९$ This work is licensed under a Creative Commons EY NG ND Attribution-NonCommercial-NoDerivatives 4.0 International (CC BY-NC-ND 4.0) License. 